\title{
Apreensões da paisagem e leituras do espaço: a Estação da Luz entre as práticas cotidianas e as imagens de cartão-postal
}

\author{
Lindolfo Campos Sancho ${ }^{1}$
}

\section{Resumo}

Esta pesquisa propõe apontar as potencialidades de construções simbólicas da Estação da Luz, em São Paulo, a partir de uma contraposição entre os usos cotidianos de seu espaço e suas imagens de "cartão-postal" que podem possibilitar a leitura de um espaço "normatizado", com funções e modos de uso específicos.

Com o objetivo de preencher o espaço arquitetônico da Estação da Luz com a presença humana em suas práticas do dia a dia, foi necessária a formulação de uma questão que implica a tomada de algumas posições teóricas. De que forma a mobilização da paisagem, em seus recortes que influenciam o olhar que se põe sobre um lugar, e as maneiras de utilização do espaço, que por sua vez influenciam ou são influenciadas pela forma de apreender a paisagem, produzem no espaço significados que o transformam em um lugar com características e valores específicos?

Ao realizar uma reflexão sobre a existência da Estação da Luz enquanto um produto sociocultural sujeito a múltiplas leituras e construções simbólicas, esta pesquisa mobiliza algumas questões e ferramentas metodológicas propostas pela Antropologia Urbana:

\footnotetext{
1 Universidade Federal de São Paulo - Graduação em Ciências Sociais. Monografia em desenvolvimento (2014). Orientador: Andréa Barbosa.

E-mail: lindolfocampos@gmail.com
} 
Nesta relação entre espaço e a sociedade que o ocupa, uma das questões mais interessantes a surgir sob uma perspectiva antropológica é a das práticas cotidianas do espaço. Práticas que são influenciadas pelos significados do espaço, e que a ele imputam novos significados. Que em relação ao espaço em que ocorrem evidenciam fronteiras simbólicas, visões de mundo, relações de poder e muitos outros aspectos da vida social.

É uma questão que ganhou corpo na obra de Michel de Certeau. Em “A invenção do cotidiano" (1996), Certeau procura demarcar um campo de pesquisa na Antropologia em que o foco de análise das representações é transferido das grandes instituições para a circulação e consumo dessas representações na vida cotidiana. Em suas palavras, "a presença e a circulação de uma representação [...] não indicam de modo algum o que ela é para seus usuários. É ainda necessário analisar sua manipulação pelos praticantes que não a fabricam" (1996: 40).

Nesta relação entre representação e práticas em que relações de poder são identificadas, o consumo do espaço é eleito por Certeau um objeto de investigação privilegiado. Aponta que há um descompasso entre o conhecimento existente sobre a cidade e o conhecimento sobre a vida urbana que nela ocorre. É uma crítica ao discurso sobre a cidade produzido pelo planejamento urbano. Um discurso que cria espaços geometrizados, ordenados e controlados. Que dá a cidade uma forma física que transmite a quem a utiliza as maneiras "certas" de utilizá-la.

Assim, o que ele chama de "saber ótico da cidade" é um saber que permite conhecer a cidade a partir da apreensão de sua paisagem urbana, em que o conhecimento sobre seu espaço depende do que é possível ler da forma do território, do sistema de ruas e avenidas, da altura dos prédios, e etc. É 
um saber nascido do voyeurismo que, aponta Certeau, tem como "condição o esquecimento e desconhecimento das práticas" (1996: 171).

Opondo este modo panorâmico de representar à cidade ao que pode ser descoberto por um engajamento no próprio espaço urbano, ao nível da rua, Certeau anuncia a problemática em que a Antropologia mobiliza o espaço como parte do problema de pesquisa da melhor forma:

"[...] eu gostaria de detectar práticas estranhas ao espaço "geométrico" ou "geográfico" das construções visuais, panóticas ou teóricas. Essas práticas do espaço remetem a uma forma específica de "operações" (maneiras de fazer), a "uma outra espacialidade" (uma experiência antropológica, poética e mítica do espaço) e a uma mobilidade opaca e cega da cidade habitada. Uma cidade transumante, ou metafórica, insinua-se assim no texto claro da cidade planejada e visivel" (1996: 172).

A partir disto, tomou forma na antropologia um campo demarcado pela oposição entre o normativo e o "tático" (para usar um termo de Certeau), entre o planejado e o não planejado, entre a tensão do poder entre a produção de representações oficiais que normatizam o espaço e o seu consumo e ressignificações pelas pessoas comuns no cotidiano. Essa oposição ganhou clareza no espaço urbano. Na oposição entre as pedras que dão forma à cidade, e as pessoas que dão forma à vida urbana.

Influenciado por Certeau, o antropólogo Antônio Augusto Arantes recorre a uma abordagem metodológica que rompe com o voyeurismo que produz um "saber ótico sobre a cidade". Arantes recorre ao que ele chama "uma certa flânerie etnográfica" (2000: 128). Uma imersão do observador no fluxo dos caminhos da cidade em que o saber produzido agora é fruto de uma visão posta em movimento, ao caminhar. 
Tornando-se um caminhante, o antropólogo pode conhecer esta vida urbana que o espaço arquitetônico não enuncia totalmente. Nas palavras de Certeau, "Os jogos dos passos moldam espaços. Tecem os lugares. Sob esse ponto de vista, as motricidades dos pedestres formam um desses "sistemas reais cuja existência faz efetivamente a cidade, mas não tem nenhum receptáculo físico" (1996: 176).

Este espaço praticado que existe em relação ao espaço planejado, portanto, pode ser uma espacialização efêmera. Relacionam-se, atualizandoos ou modificando-os culturalmente, com os significados e imagens do espaço produzidas por quem o planeja. E é justamente por não estar permanentemente inscrito no espaço físico que estes antropólogos levantaram este problema com uma crítica ao urbanismo como o conhecemos, ao saber da cidade produzido na imagem de um panorama, de um olhar fixo no topo de um arranha-céu, tão longe do fluxo das ruas.

Na própria arquitetura há um debate que reconhece que o tecnicismo pode limitar o objetivo de atender as demandas da sociedade. E que o urbanismo enquanto planejamento do espaço urbano institucionalizado pode ser opressor se não procurar incorporar o dinamismo da vida ao seu planejamento de longa duração.

$\mathrm{O}$ arquiteto italiano Francesco Careri, inclusive, apontou para essas limitações e, sob uma perspectiva interdisciplinar, propôs novas ferramentas para uso os arquitetos que se assemelham muito com as abordagens metodológicas de Certeau e Arantes. Em "Walkscapes: o caminhar como prática estética" (2013), Careri problematiza a perspectiva da arquitetura sobre os espaços vazios da cidade. Propõe instrumentos e técnicas para intervir nestes vazios urbanos por meio de uma prática chamada 
transurbância, que consiste em identificar os aspectos efêmeros da paisagem, que atualizam o significado do espaço:

"Além dos sistemas de assentamento, dos traçados, das ruas e das casas, existe uma enorme quantidade de espaços vazios que compõem o pano de fundo sobre o qual a cidade se autodefine. São diferentes dos espaços vazios tradicionalmente entendidos como espaços públicos - praças, bulevares, jardins, parques - e formam uma enorme porção de território não construído, utilizada e vivida de modos infinitos e que às vezes resulta absolutamente impenetrável. Os vazios são parte fundamental do sistema urbano e são espaços que habitam a cidade de modo nômade, deslocam-se sempre que o poder tenta impor uma nova ordem." (2013: 157).

"Habitar a cidade de modo nômade". Entendendo que esta maneira de habitar e entender o espaço não é oposta a cidade, como concebida pela arquitetura tradicional, mas algo característico do sistema urbano, presente na cidade enquanto espaços de fluxo que permeiam as ilhas sedentárias, o caminhar é proposto aqui como instrumento disponível à arquitetura (a qualquer um que se propõe a investigar o espaço urbano, na verdade), para identificar e entender esta cidade nômade que habita a cidade oficial.

Em "Paisagens Paulistanas", Arantes levanta o problema da estruturação do espaço por grupos que o usam de modos contrastantes, e até conflituosos - seja entre os grupos que habitam a cidade, ou entre esses grupos e a administração pública. Esta estruturação é apreendida pela identificação de suas fronteiras simbólicas, dos significados imputados por estes grupos. Sua hipótese é a de que "a experiência urbana contemporânea propicia a formação de uma complexa arquitetura de territórios, lugares e não-lugares, que resulta na formação de configurações espaço-temporais 
mais efêmeras e híbridas (2000: 106)". É muito semelhante à experiência urbana que ocorre nos espaços que Careri chama de "vazios urbanos".

Para conhecer esta cidade nômade, Careri propõe a mesma abordagem de Certeau, a de colocar o olhar em movimento. Caminhar e identificar lugares no percurso:

"O caminhar, mesmo não sendo a construção física de um espaço, implica uma transformação do lugar e dos seus significados.

A presença física do homem num espaço não mapeado - e o variar das percepções que daí ele recebe ao atravessá-lo - é uma forma de transformação da paisagem que, embora não deixe sinais tangíveis, modifica culturalmente o significado do espaço e, consequentemente, o espaço em si, transformando-o em lugar. O caminhar produz lugares". (2013: 51)

Ou seja, é necessário pôr os olhos a caminhar para identificar os espaços produzidos pelos jogos dos passos. Os problemas levantados por estes autores, junto as suas propostas de abordagem metodológica, são o ponto de partida para a investigação do espaço da Estação da Luz. Um espaço arquitetônico, sujeito a construções simbólicas que acompanham a história da cidade, com uma administração oficial que determina seus usos, ao mesmo tempo em que é apropriado pela população das maneiras mais diversas.

$\mathrm{Na}$ base desta pesquisa, portanto, está a ideia de que o espaço arquitetônico, por mais permanente que seja em sua forma, está sujeito a uma série de ocupações, ou práticas, que lhe preenchem de significados mais duradouros ou efêmeros. E o estudo da paisagem urbana na qual este lugar está inserido deve evidenciar esta relação entre "estratégias" e "táticas" na forma de utilizar o espaço. O que demanda esclarecer a distinção entre 
espaço e paisagem para que seja possível estabelecer uma relação entre estas duas categorias.

O geógrafo Milton Santos diz que paisagem e espaço são como aquelas coisas com "duplo rosto" (2006: 67). Diz ele que diante destas categorias, "corremos o risco de não distinguir essas duas faces ou de separálas de tal modo que acabamos por apenas considerar uma só face de cada vez" (idem). Diz isso porque defende uma separação conceitual entre essas duas categorias:

"A paisagem é o conjunto de formas que, num dado momento, exprimem as heranças que representam as sucessivas relações localizadas entre homem e natureza. O espaço são essas formas mais a vida que as anima". (2006: 66)

Para Santos a paisagem possui uma dimensão concreta. É a porção da configuração territorial que pode ser abarcada com a visão (2006: 67). O espaço tem seu valor definido pela sociedade a partir do valor que esta atribui a sua paisagem. Ou seja, a partir de como uma porção de um território com uma forma específica, e uma disposição específica dos objetos que o compõem, pode desempenhar uma função determinada pela sociedade. Santos acaba por definir o espaço como um conjunto de mercadorias por entendê-lo sob esta ótica em que possui uma função atribuída pela sociedade.

Para ele, portanto, a paisagem é um conjunto material formado com o passar do tempo. Possui o passado e o presente em seu conjunto. Já o espaço é um sistema de valores. É a função que esta paisagem ocupa no tempo presente. Ou seja, a paisagem (forma), se torna espaço quando ganha um valor, quando é utilizada pela sociedade (forma - conteúdo). Ao mesmo tempo, o espaço é pensado como "uma síntese, sempre provisória, entre o conteúdo social e as formas espaciais" (2006: 71). 
A distinção feita por Santos é importante. Mas a categoria paisagem aparece limitada a uma forma física do território desprovida de valor. Desprovida da própria sociedade que produz o espaço:

"Durante a guerra fria, os laboratórios do Pentágono chegaram a cogitar a produção de um engenho, uma bomba de nêutrons, capaz de aniquilar a vida humana em uma dada área, mas preservando todas as construções. $O$ Presidente Kennedy afinal renunciou a levar a cabo esse projeto. Senão, o que na véspera seria ainda o espaço, após a temida explosão seria apenas paisagem. Não temos melhor imagem para mostrar a diferença entre esses dois conceitos" (2006: 69).

Enquanto sob a perspectiva de Santos a paisagem pode existir sem a presença humana, Simmel diz que é justamente o olhar humano que cria a paisagem.

A forma do território em si não é suficiente para configurar uma paisagem, segundo Simmel (1996: 16). É a delimitação visual de uma porção do território percebida enquanto uma unidade que configura uma paisagem. Esta é, portanto, um produto do espírito.

Este recorte visual do território pode ser resultado de uma forma específica de utilizar o território, mas não necessariamente. Não é simplesmente uma configuração formal do território independente do homem, mas uma configuração simbólica da forma do território.

Francesco Careri entende a paisagem como uma “[...] transformação simbólica, para além de física, do espaço antrópico" (2013: 28). Pensando no espaço de maneira geral, a paisagem nestes dois autores (Careri e Simmel) é uma obra do homem em sua dimensão simbólica. Ao passo que na 
perspectiva de Santos esta dimensão simbólica é conferida ao espaço, sendo o valor da paisagem dependente deste espaço.

Esta pesquisa considera, portanto, que a paisagem é um fragmento do território abarcado pela visão. Não existe sem a presença humana. Está sujeita a uma série de construções simbólicas operadas pela atribuição de valores a seus aspectos formais, que podem estar ligados a várias formas de utilizar o espaço. Ou seja, em um raio de visão, podemos construir várias paisagens.

Palavras Chave: antropologia do espaço; práticas cotidianas; antropologia e arquitetura; paisagem urbana

\section{Referências}

AGIER, Michel. Lugares e redes: as mediações da cultura urbana. In: GODOI, Emília Pietrafesa de; NIEMEYER, Ana Maria de (orgs.). Além dos territórios: para um diálogo entre a etnologia indígena, os estudos rurais e os estudos urbanos. Campinas: Editora Mercado de Letras, 1998.

ARANTES NETO, Antônio Augusto. Paisagens paulistanas: transformações do espaço público. Campinas, SP: Editora da Unicamp; São Paulo: Imprensa Oficial, 2000.

CARERI, Francesco. Walkscapes: o caminhar como prática estética. São Paulo: Editora G. Gili, 2013.

CERTEAU, Michel de. A invenção do cotidiano: 2. morar, cozinhar. Petrópolis, RJ: Vozes, 1996.

CORDEIRO, Graça Índias. A antropologia urbana entre a tradição e a prática. In: BAPTISTA, Luís Vicente; CORDEIRO, Graça Índias; COSTA, António Firmino da (orgs.). Etnografias urbanas. Oeiras: Celta Editora, 2003.

EVANS-PRITCHARD, E.E. (Edward Evan). Os nuer: uma descrição do modo de subsistência e das instituições políticas de um povo nilota. São Paulo: Perspectiva, 2005.

LÉVI-STRAUSS, Claude. Tristes trópicos. São Paulo: Companhia das Letras, 1996. 
PARK, Robert Ezra. A cidade: sugestões para a investigação do comportamento humano no meio urbano. In: VELHO, Otávio Guilherme (org.). O fenômeno urbano. Rio de janeiro: Zahar Editores, 1979.

SANTOS, Milton. A natureza do espaço: técnica e tempo, razão e emoção. São Paulo: Editora da Universidade de São Paulo, 2006.

SIMMEL, Georg. A filosofia da paisagem. In: Revista Política e Trabalho. PPGSUFPb, n. 12 , set/1996. 